\title{
Development and characterization of mouse monoclonal antibodies targeting to distinct epitopes of Zika virus envelope protein for specific detection of Zika virus
}

\author{
Chia-Jung $\mathrm{Li}^{1} \cdot$ Ping-Han Huang ${ }^{2} \cdot$ Hui-Wen Chen ${ }^{2} \cdot$ Shih-Chung Chang ${ }^{1,3}$ (D) \\ Received: 5 February 2021 / Revised: 7 May 2021 / Accepted: 20 May 2021 / Published online: 27 May 2021 \\ (C) The Author(s), under exclusive licence to Springer-Verlag GmbH Germany, part of Springer Nature 2021
}

\begin{abstract}
The recent Zika virus (ZIKV) epidemic poses a serious threat to global health due to its association with microcephaly and congenital diseases in newborns and neurological complications and Guillain-Barré syndrome in adults. However, the majority of people infected with ZIKV do not develop symptoms. The platforms aimed to specifically diagnose ZIKV infection are needed for patient care and public health surveillance. In the study, four ZIKV envelope (E) protein-specific monoclonal antibodies (mAbs) (A1, B1, C1, and 9E-1) have been developed by using the conventional mAb technology. The binding epitopes of mAbs $\mathrm{A} 1, \mathrm{~B} 1, \mathrm{C} 1$, and 9E-1 are located at E(238-257), E(410-431), E(258-277), and E(340-356), respectively. mAb 9E-1 performs 1.4to 47 -fold strong affinity to ZIKV E protein compared to another three mAbs. mAbs A1, C1, and 9E-1 do not have crossreactivity against the recombinant $\mathrm{E}$ proteins of dengue virus serotypes 2, 3, and 4. Although these four mAbs do not have ZIKV neutralizing activity, mAbs B1 and 9E-1 have been developed as the lateral flow immunochromatographic assay for specific detection of ZIKV E protein and virions.
\end{abstract}

\section{Key points}

- The mAbs targeting to the regions of E(238-257), E(410-431), E(258-277), and E(340-356) do not have ZIKV neutralizing activity.

- The binding epitope of mAb 9E-1 is highly specific to ZIKV E protein.

- $m A b s$ BI and 9E-1 can bind to ZIKV virions and have been developed as the lateral flow immunochromatographic assay.

Keywords Zika virus $\cdot$ Envelope protein $\cdot$ Monoclonal antibody $\cdot$ Lateral flow immunochromatographic assay

\section{Introduction}

Zika virus (ZIKV) was first isolated from Rhesus macaque monkeys in Uganda in 1947. After that, only a few ZIKV human infection cases were reported until the first cluster outbreak in the Yap Island of the Federated States of Micronesia in 2007 and the second ZIKV epidemic outbreak in French

Shih-Chung Chang

shihchung@ntu.edu.tw

1 Department of Biochemical Science and Technology, College of Life Science, National Taiwan University, Taipei 106, Taiwan

2 Department of Veterinary Medicine, National Taiwan University, Taipei 106, Taiwan

3 Center of Biotechnology, National Taiwan University, Taipei 106, Taiwan
Polynesia and other countries and territories in the Pacific during 2013-2014 (Kindhauser et al. 2016). Outbreaks soon appeared throughout the Americas, Africa, and other regions of the world. To date, a total of 87 countries and territories have reported evidence of ZIKV infection.

ZIKV is primarily transmitted by infected mosquitoes from the Aedes genus (Marchette et al. 1969) in tropical and subtropical regions. The incubation period of ZIKV disease is estimated to be 3-14 days. The symptoms of ZIKV infection are generally mild and similar to those caused by other flaviviruses such as dengue virus (DENV) and West Nile virus (WNV). In fact, the majority of people infected with ZIKV do not develop symptoms. However, ZIKV infection during pregnancy can result in stillbirth and preterm birth and also cause infants to be born with microcephaly and other congenital malformations, known as congenital Zika syndrome. An increased risk of neurologic complications is associated with 
ZIKV infection in adults and children, including GuillainBarré syndrome, neuropathy, and myelitis. In addition to blood, ZIKV can also be detected in urine (Gourinat et al. 2015), saliva (Musso et al. 2015), and breast milk (DupontRouzeyrol et al. 2016).

Antibodies raised by different flaviviruses often have broad efficacy. For example, most of the anti-dengue antibodies isolated from patients infected by DENV can bind to ZIKV (Gunawardana and Shaw 2018; Priyamvada et al. 2016; Swanstrom et al. 2016). More importantly, there is no treatment available for ZIKV infection or its associated diseases, and no vaccine is yet available for prevention of ZIKV infection. Therefore, development of antibodies that can specifically recognize ZIKV must be undertaken to establish the accurate method for diagnostics of ZIKV infection.

The surface of ZIKV is covered by envelope (E) proteins, which are responsible for the virus to bind to host cell surface receptor (Perera-Lecoin et al. 2013). The ZIKV E protein consists of domain I, domain II, domain III, and stemtransmembrane domain and exists in the form of dimers, arranging on the outer side of the viral membrane. The important function of the ZIKV E protein and its characteristics of covering the outermost layer of ZIKV make it the major target of neutralizing antibodies. In the present study, four mouse monoclonal antibodies (mAbs) A1, B1, C1, and 9E-1 targeting to the spatially distinct epitopes of ZIKV E protein were generated by the conventional hybridoma technology. Although these four mAbs do not have ZIKV neutralization activity, mAbs B1 and 9E-1 containing great ability for binding to ZIKV virions have been developed as the lateral flow immunochromatographic assay (LFIA) for detection of ZIKV specifically.

\section{Materials and methods}

\section{The ZIKV E protein}

The cDNA encoding for the ZIKV E protein of strain Thailand/1610acTw (GenBank accession number MF692778.1) was synthesized (GenScript Inc.) and then subcloned into the pFastBac vector (Thermo Fisher Scientific Inc.) with an $\mathrm{N}$-terminal signal peptide MKFLVNVALVFMVVYISYIYA, an N-terminal hexa-histidine tag (His-tag), a Tobacco Etch Virus (TEV) protease recognition sequence ENLYFQG, and a C-terminal His-tag. The pFastBac-ZIKV E plasmid was transformed into DH10bac competent cells for preparation of the bacmid. The purified bacmid was subsequently transfected into $\mathrm{Sf} 21$ insect cells by using the Cellfectin II reagent according to the instruction of the Bac-to-Bac baculovirus expression system (Thermo Fisher Scientific Inc.). Sf21 insect cells were infected by the baculovirus containing ZIKV E gene at a multiplicity of infection (MOI) of 1 pfu/cell. The recombinant ZIKV E proteins were expressed as inclusion bodies and purified by using a HisTrap FF column (GE Healthcare) pre-equilibrated with a binding buffer ( $10 \mathrm{mM}$ sodium phosphate, $10 \mathrm{mM}$ imidazole, $0.5 \mathrm{M} \mathrm{NaCl}$, and $8 \mathrm{M}$ urea, $\mathrm{pH}$ 7.4). The bound recombinant ZIKV E proteins were eluted with a linear gradient of $10-500$ $\mathrm{mM}$ imidazole buffer. Protein purity was examined by SDSPAGE, and concentration was determined by Bradford dyebinding method (Bradford 1976).

\section{The DENV E proteins}

The recombinant DENV serotype 2 (DENV2) E protein (GenBank: AAC59274.1), serotype 3 (DENV3) E protein (GenBank: AAA99437.1), and serotype 4 (DENV4) E protein (GenBank: AAX48017.1) were purchased from Sino Biological Inc. (Catalog Number: 40471-V08B, 40532V08H1, and 40533-V08B2, respectively).

\section{Preparation of mouse $\mathrm{mAb}$ against ZIKV E protein}

For generation of the mouse $\mathrm{mAb}$ against ZIKV E protein, two BALB/c male mice were immunized through intraperitoneal injection with a mixture of purified ZIKV E protein and complete or incomplete Freund's adjuvant (Sigma-Aldrich, USA) in a 2-week interval, followed by a final booster injection of $50 \mu \mathrm{g}$ purified ZIKV E protein in phosphate buffered saline (PBS). The procedures for generation of hybridomas were performed as described previously (Cheng and Chang 2021). In brief, the myeloma Sp2/0-Ag 14 cells (ATCC CRL1581) were mixed with mouse splenocytes from donor mice in a 1:5 ratio of cell numbers. The $0.7 \mathrm{~mL}$ of polyethylene glycol 1500 (Sigma-Aldrich, USA) was added to the cell mixture and incubated in a $37^{\circ} \mathrm{C}$ water bath for $2 \mathrm{~min}$ with gentle shaking. The additional $10 \mathrm{~mL}$ of Dulbecco's Modified Eagle Medium (DMEM) was then added to the cell mixture within $4 \mathrm{~min}$. Cells were collected by centrifugation and resuspended in 30 $\mathrm{mL}$ of DMEM with $15 \%$ fetal bovine serum, $1 \%$ penicillinstreptomycin, $1 \mathrm{mM}$ sodium pyruvate (Thermo Scientific, USA), HybriMore Hybridoma Culture Supplement (Energenesis Biomedical, Taipei, Taiwan), and HAT media supplement (Sigma-Aldrich, USA). Fusion cells $(0.1 \mathrm{~mL})$ were then cultured in the 96 -well cell culture plates at $37^{\circ} \mathrm{C}$ in the $5 \% \mathrm{CO}_{2}$ incubator. On day 7 after cell fusion, $50 \mu \mathrm{L}$ of HT media supplement (Sigma-Aldrich, USA) was added to the culture media. ELISA analysis was performed to screen the positive hybridoma clones. The mAbs were further obtained by limiting dilution method. To purify the mAbs, the hybridoma cell culture media were filtered with $0.45 \mu \mathrm{m}$ membrane disc and then purified by HiTrap Protein G HP column (GE Healthcare). The purified antibody sample was dissolved in PBS, and the concentration was determined by Bradford dye-binding method using mouse IgG as the standard. 


\section{Enzyme-linked immunosorbent assay (ELISA)}

The specificity of $\mathrm{mAb}$ against ZIKV E protein and virions was determined by using an indirect ELISA method. In brief, the wells of a 96-well plate pre-coated with $100 \mathrm{ng}$ of ZIKV E protein or virions were blocked with $0.25 \%$ gelatin in PBS buffer containing $0.05 \%$ Tween-20 (PBST) and then incubated with mAbs at room temperature for $1 \mathrm{~h}$. After washing the 96-well plate three times with PBST, the HRP-conjugated goat anti-mouse IgG (H+L) (KPL, USA) was added to each well and incubated at room temperature for an additional $1 \mathrm{~h}$. After washing the 96-well plate three times with PBST, $75 \mu \mathrm{L}$ of 3,3',5,5'-tetramethylbenzidine (TMB) substrate (BD Bioscience, USA) was added to each well for signal detection, and $75 \mu \mathrm{L}$ of $2 \mathrm{~N} \mathrm{H}_{2} \mathrm{SO}_{4}$ was added to terminate the reactions. Results are evaluated quantitatively by measuring the absorbance at $450 \mathrm{~nm}$.

\section{Determination of the binding affinity of $\mathrm{mAb}$ against ZIKV E protein}

The purified ZIKV E proteins in $10 \mathrm{mM}$ sodium acetate buffer (pH 4) were covalently immobilized on the surface of the Sensor Chip CM5 (GE Healthcare Life Sciences) using standard amine coupling to a level of larger than 2000 response units (RU) read by the Biacore T200 (GE Healthcare Life Sciences). The antibody solutions were pre-concentrated to $1 \mathrm{mM}$ and then diluted to $500,250,125,62.5,31.25,15.65$, 7.8, and $3.9 \mathrm{nM}$ in a two-fold dilution manner. Analysis was performed by injecting the antibody samples over the CM5 surface for $2 \mathrm{~min}$ to measure the RU in the association reaction and then injecting a continuous flow of PBST running buffer for $20 \mathrm{~min}$ to measure the RU in the dissociation reaction. Regeneration was performed by injecting the $10 \mathrm{mM}$ glycine- $\mathrm{HCl}(\mathrm{pH} \mathrm{3.0)}$ ) buffer to remove the bound antibodies on the CM5 surface and then equilibrated the sensor chip with PBST for analyzing the next antibody sample. A sensorgram was plotted in the combination of RU against time, showing the progress of the interaction. The kinetic parameters of $k_{\mathrm{on}}$, $k_{\mathrm{off}}$, and $K_{\mathrm{D}}$ of the specific mAb against the ZIKV E protein were calculated by using the Biacore T200 built-in fitting curve method.

\section{Expression of the truncated ZIKV E protein fragments}

The molecular structure of ZIKV E protein can be divided into domain I (composed of residues 1-51, 132-192, and 280-298), domain II (composed of residues 52-131 and 193-279), domain III (residues 298-409), and stem domain (residues 410454). The truncated ZIKV E protein fragments were mainly designed and constructed according to the regions of the domain structures mentioned above. For constructing more truncated ZIKV E protein fragments, some N-terminal residues of domain II, domain III, and stem domain were also sequentially deleted. The cDNAs encoding for the truncated ZIKV E protein fragments were cloned into the pGEX-4T-1 vector with an N-terminal GST tag and a C-terminal His-tag and transformed into E. coli BL21(DE3) competent cells. The protein expression procedure was conducted as described previously (Shin et al. 2011) with slight modifications. Briefly, E. coli BL21(DE3) cells containing with the vectors of pGEX-4T-1ZIKV E protein fragments were cultured in LB medium with ampicillin $(50 \mu \mathrm{g} / \mathrm{mL})$ at $37^{\circ} \mathrm{C}$ on an orbital shaker. IPTG (1 $\mathrm{mM}$ ) was utilized to induce the expression of the recombinant GST-tagged truncated ZIKV E protein fragments at $37^{\circ} \mathrm{C}$ for $4 \mathrm{~h}$. Cells were collected by centrifugation and then subjected to SDS-PAGE and Western blotting (WB) analysis with the indicated antibodies.

\section{Plaque reduction neutralization test (PRNT)}

ZIKV isolate Thailand/1610acTw was kindly provided by the Centers of Disease Control, Taiwan, and propagated in Vero cells (\#60013, Bioresource Collection and Research Center, Hsinchu, Taiwan). Virus titers were determined by standard plaque assays. The neutralizing activity of the antibodies against ZIKV was determined. Briefly, two-fold serially diluted antibody solutions (starting from $100 \mu \mathrm{g} / \mathrm{mL}$ or $10 \mu \mathrm{g} / \mathrm{mL}$ ) were incubated with $100 \mathrm{PFU}$ of ZIKV for $1 \mathrm{~h}$ at $37^{\circ} \mathrm{C}$. Antibody-virus complexes were added to Vero cell monolayers in 12-well plates. After $2 \mathrm{~h}$, cells were washed and overlaid with $1.8 \%(\mathrm{w} / \mathrm{v})$ methylcellulose in DMEM supplemented with $2 \%$ FBS and $1 \%$ non-essential amino acid. Four days later, plates were fixed with $1 \%$ formaldehyde in PBS and stained with the crystal violet for $30 \mathrm{~min}$. Plaques were then counted and compared with PBS control to determine the neutralizing titer. The mouse anti-ZIKV E protein $\mathrm{mAb}$, clone ZV-54 (MABF2046, Merck Ltd.), with known neutralizing activity was also tested (Zhao et al. 2016).

\section{LFIA}

The mAb-colloidal gold conjugate was prepared as described previously (Chiang et al. 2021) with slight modifications. Briefly, $0.5 \mathrm{~mL}$ of colloidal gold (Excelsior Bio-System, Inc., Taipei, Taiwan) was mixed with $30 \mu \mathrm{g}$ of $\mathrm{mAb} B 1$ and $50 \mu \mathrm{L}$ of $10 \% \mathrm{NaCl}$ at room temperature for $30 \mathrm{~min}$, followed by an additional $30 \mathrm{~min}$ of stirring with $80 \mu \mathrm{L}$ of $10 \%(\mathrm{w} / \mathrm{v})$ bovine serum albumin (BSA) at room temperature to block the excess reactivity of colloidal gold. After centrifugation at $8000 \mathrm{rpm}$ for $15 \mathrm{~min}$, the $\mathrm{mAb}$ B1-colloidal gold pellet was washed with $2 \mathrm{mM}$ borate buffer containing $0.2 \%$ PEG- 8000 (pH 9.0) twice and then resuspended in $10 \mu \mathrm{L}$ of PBS. The LFIA strip consisted of four main materials, including sample pad, conjugate pad, nitrocellulose membrane, and absorbent pad (Excelsior Bio-System, Inc., Taipei, Taiwan). Then, $6 \mu \mathrm{L}$ 
of $\mathrm{mAb}$ B1-colloidal gold conjugate was loaded on the conjugate pad. Subsequently, $4.5 \mu \mathrm{g}$ of $\mathrm{mAb} 9 \mathrm{E}-1$ and $4 \mu \mathrm{g}$ of goat anti-mouse IgG (H+L) (KPL, USA) were loaded on the NC membrane separately, serving as the test line and the control line. Upon use, the test sample was added on the sample pad to start the LFIA.

\section{Results}

\section{Specificity and binding affinity of mAbs A1, B1, C1, and $9 \mathrm{E}-1$ against ZIKV E protein}

The recombinant ZIKV E proteins expressed in Sf21 insect cells were purified and utilized for immunization and induction of antibodies in BALB/c mice. After screening of the secreted antibodies by hybridomas with specificity against ZIKV E protein, mAbs A1, B1, C1, and 9E-1 were selected and subjected to further biochemical characterization. The ELISA results showed that these four mAbs can bind to the native form of ZIKV E protein (Fig. 1a). The results of the WB analysis showed that the purified ZIKV E protein samples not only contain the full length ZIKV E protein but also contain the degraded ZIKV E protein fragments (Fig. 1b). Notably, although mAbs A1, B1, C1, and 9E-1 can bind to the full length ZIKV E protein, they displayed different detection patterns for probing to degraded ZIKV E protein fragments (Fig. 1b), implying that they might bind to different regions of ZIKV E protein.

In order to analyze the binding affinity of $\mathrm{mAbs} \mathrm{A} 1, \mathrm{~B} 1$, $\mathrm{C} 1$, and 9E-1 against ZIKV E protein, the purified recombinant ZIKV E proteins were covalently immobilized on the surface of the Sensor Chip CM5 for performing the Biacore kinetics assay (Fig. $2 \mathrm{a} \sim \mathrm{d}$ ). The concentrations ( $K_{\mathrm{D}}$ values) of mAbs A1, B1, C1, and 9E-1 for binding to half of the total molecules of ZIKV E proteins on the sensor chip are $8.24 \mathrm{nM}$, $33.89 \mathrm{nM}, 1.03 \mathrm{nM}$, and $0.72 \mathrm{nM}$ (Fig. 2e). mAb 9E-1 showed 1.4- to 47-fold strong affinity to ZIKV E protein compared to another three $\mathrm{mAbs}$, indicating that $\mathrm{mAb} 9 \mathrm{E}-1$ has the highest affinity against ZIKV E protein.

\section{Epitope mapping of mAbs A1, B1, C1, and 9E-1}

As described previously, mAbs A1, B1, C1, and 9E-1 seem binding to different regions of ZIKV E protein (Fig. 1b). To determine the binding epitopes of $\mathrm{mAbs} \mathrm{A} 1, \mathrm{~B} 1, \mathrm{C} 1$, and 9E1, a series of truncated ZIKV E protein fragments (Fig. 3a) were generated and utilized for performing the epitope mapping experiments by WB analysis. The $\mathrm{mAb} \mathrm{A} 1$ can bind to $\mathrm{E}(238-298)$, but cannot bind to $\mathrm{E}(258-298)$ and $\mathrm{E}(278-298)$ (Fig. 1a), indicating that the binding epitope of $\mathrm{mAb} A 1$ is located at the region of $\mathrm{E}(238-257)$. The $\mathrm{mAb} \mathrm{B} 1$ can bind to $\mathrm{E}(410-454)$, but cannot bind to $\mathrm{E}(1-298), \mathrm{E}(298-409)$, and $\mathrm{E}(432-454)$ (Fig. 3b), indicating that the binding epitope of $\mathrm{mAb} \mathrm{B} 1$ is located at the region of $\mathrm{E}(410-431)$. The $\mathrm{mAb} \mathrm{C1}$ can bind to $\mathrm{E}(258-298)$ and other N-terminally truncated fragments, but cannot bind to $\mathrm{E}(278-298)$ (Fig. 3c), indicating that the binding epitope of $\mathrm{mAb} \mathrm{C1}$ is located at the region of $\mathrm{E}(258-277)$. The mAb 9E-1 can bind to $\mathrm{E}(298-409)$, $\mathrm{E}(335-$ 409), and $\mathrm{E}(340-409)$, but cannot bind to $\mathrm{E}(357-409)$ (Fig. $3 \mathrm{~d}$ ), indicating that the binding epitope of $\mathrm{mAb} 9 \mathrm{E}-1$ is located at the region of $\mathrm{E}(340-356)$.

To conclude the results of the epitope mapping experiments, a dimeric form of ZIKV E protein (Protein Data a

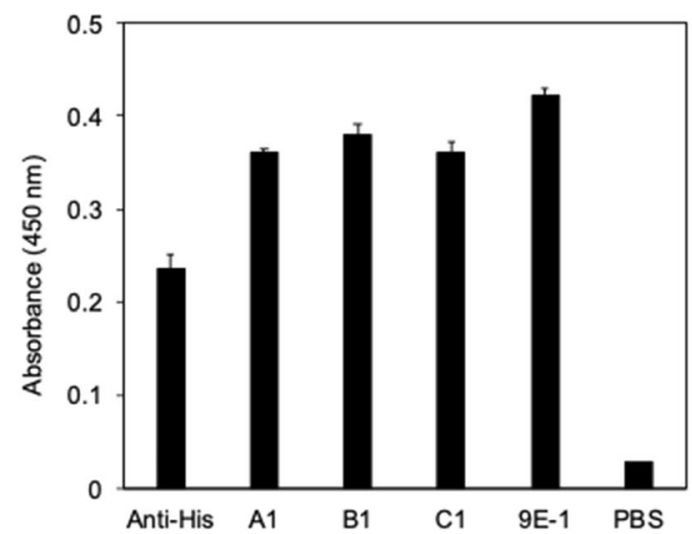

Fig. 1 The binding specificity of mAbs A1, B1, C1, and 9E-1 against ZIKV E protein. a The His-tagged ZIKV E protein (100 ng) was coated on a 96-well plate and then subjected to ELISA analysis with mAbs AntiHis, A1, B1, C1, or 9E-1, respectively. The detailed experimental procedures were described in the "Materials and methods" section. The results of the ELISA analysis were evaluated quantitatively by measuring the

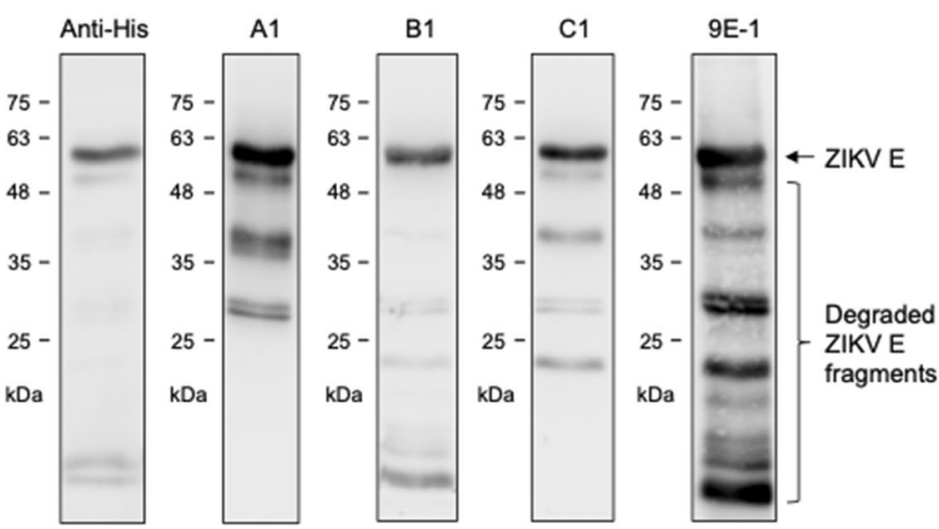

absorbance at $450 \mathrm{~nm}$. Values are means \pm S.D. from three independent experiments. b The recombinant ZIKV E protein expressed in Sf2 1 insect cells $(2 \mu \mathrm{g})$ was separated on SDS-PAGE and then transferred to a PVDF membrane for performing the WB analysis with mAbs Anti-His, A1, B1, $\mathrm{C} 1$, or 9E-1, respectively. The numbers labeled on the left of the designated ticks are the molecular weight standards in $\mathrm{kDa}$ unit 
a

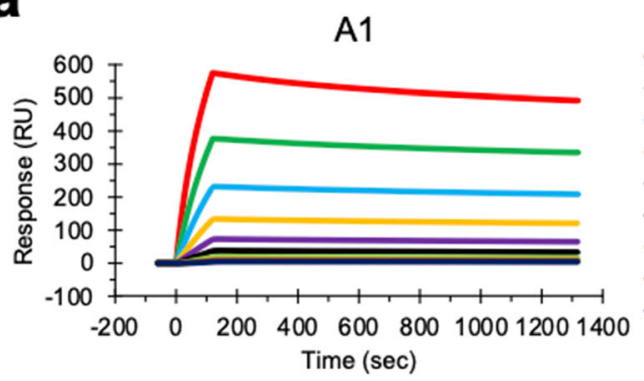

C

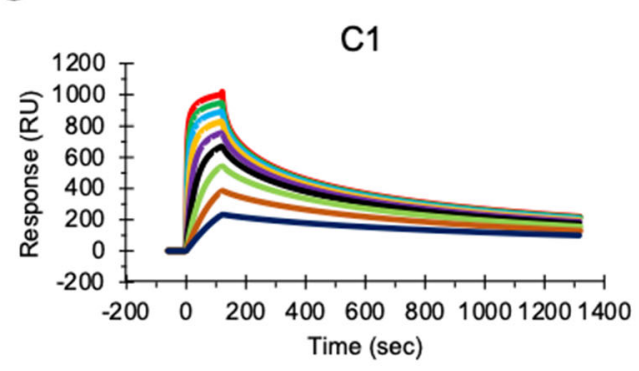

$\mathbf{e}$

\begin{tabular}{cccc}
\hline $\mathrm{mAb}$ & $k_{\text {on }}(1 / \mathrm{Ms})$ & $k_{\text {off }}(1 / \mathrm{s})$ & $K_{\mathrm{D}}(\mathrm{nM})$ \\
\hline $\mathrm{A} 1$ & $1.36 \mathrm{E}+4$ & $1.12 \mathrm{E}-4$ & 8.24 \\
$\mathrm{~B} 1$ & $2.29 \mathrm{E}+4$ & $7.76 \mathrm{E}-4$ & 33.89 \\
$\mathrm{C} 1$ & $2.06 \mathrm{E}+6$ & $2.13 \mathrm{E}-3$ & 1.03 \\
$9 \mathrm{E}-1$ & $3.40 \mathrm{E}+4$ & $2.44 \mathrm{E}-5$ & 0.72 \\
\hline
\end{tabular}

Fig. 2 Determination of the binding affinity of mAbs A1, B1, C1, and 9E-1 against ZIKV E protein. The kinetics assays by surface plasmon resonance (SPR) analysis were performed with a series of two-fold diluted mAbs A1, B1, C1, and 9E-1 solutions (starting from 1,000 to 3.90625 $\mathrm{nM}$ ) and the purified recombinant ZIKV E proteins, which were covalently immobilized on the surface of the Sensor Chip CM5 as described in

Bank identification code: 5IRE) was utilized for marking the binding epitopes of mAbs A1, B1, C1, and 9E-1 (Fig. 4). Notably, the binding epitope of mAb A1 (Fig. 4a, orange color) is buried underneath two surface beta-sheets. The binding epitope of $\mathrm{mAb} \mathrm{C1}$ (Fig. 4a, green color) is located in the interface between two subunits and is also located away from the surface of ZIKV E protein. The binding epitope of mAb B1 (Fig. 4a, purple color) is located near the stem domain of ZIKV E protein. The binding epitope of mAb 9E-1 (Fig. 4a, cyan color) is located in the domain III of ZIKV E protein.

Since flavivirus E proteins share $\sim 40 \%$ amino acid identity (Roby et al. 2015; Slon Campos et al. 2018), the corresponding sequences of $\mathrm{E}$ proteins derived from different mosquitoborne flaviviruses, such as ZIKV, DENV, WNV, yellow fever virus (YFV), and Japanese encephalitis virus (JEV), were aligned with the binding epitopes of $\mathrm{mAbs} \mathrm{A} 1, \mathrm{~B} 1, \mathrm{C} 1$, and 9E-1 to predict the immunological cross-reactivity (Fig. 5). Some amino acid sequences of the binding epitopes of b

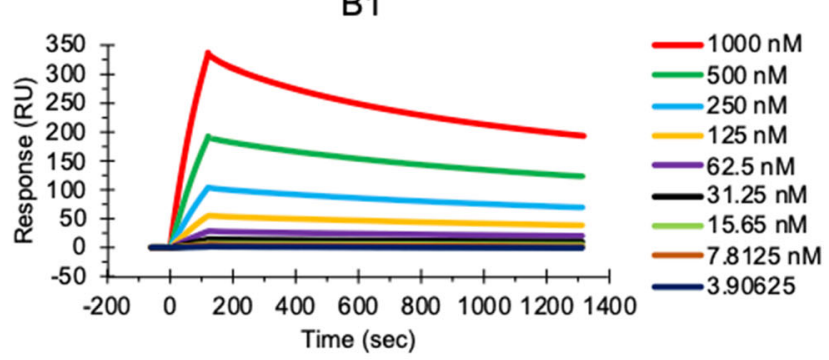

d

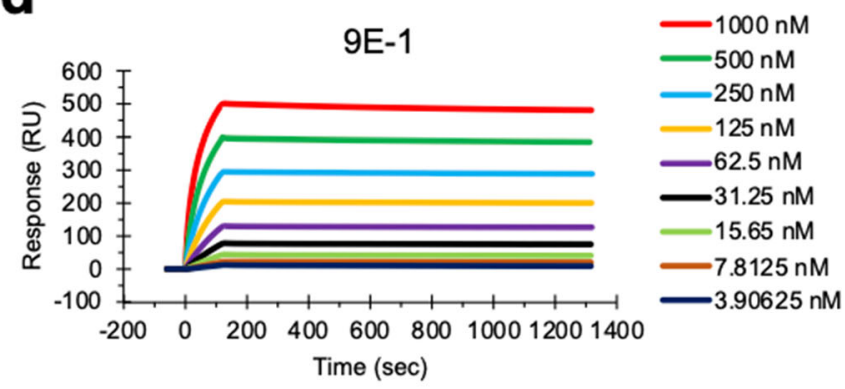

the "Materials and methods" section. a The SPR sensogram of mAb A1 interacting with ZIKV E protein. b The SPR sensogram of $\mathrm{mAb} B 1$ interacting with ZIKV E protein. $\mathbf{c}$ The SPR sensogram of $\mathrm{mAb} \mathrm{C} 1$ interacting with ZIKV E protein. d The SPR sensogram of mAb 9E-1 interacting with ZIKV E protein. e The list of $k_{\mathrm{on}}, k_{\mathrm{off}}$, and $K_{\mathrm{D}}$ values of mAbs A1, B1, C1, and 9E-1 against ZIKV E protein

mAbs $\mathrm{A} 1, \mathrm{~B} 1$, and $\mathrm{C} 1$ are conserved with the $\mathrm{E}$ proteins of DENV, WNV, YFV, and JEV (Fig. 5a-c), implying that they might have certain levels of cross-reactivity against different flavivirus $\mathrm{E}$ proteins. In contrast, the sequence of the binding epitope of $\mathrm{mAb} 9 \mathrm{E}-1$ is not well conserved with the $\mathrm{E}$ proteins of DENV, WNV, YFV, and JEV (Fig. 5d), suggesting that mAb 9E1 might be highly specific for recognition of ZIKV E protein. To further examine the cross-reactivity of mAbs A1, $\mathrm{B} 1, \mathrm{C} 1$, and 9E-1 against the representative DENVs, the recombinant $\mathrm{E}$ proteins of DENV2, DENV3, and DENV4 were applied in the WB analysis. Since the binding epitope of $\mathrm{mAb}$ $\mathrm{B} 1$ is not included in the recombinant $\mathrm{E}$ proteins of DENV2, DENV3, and DENV4, it can only detect the ZIKV E protein (Fig. 5e). Surprisingly, the results showed that mAbs A1, C1, and 9E-1 do not have cross-reactivity against the E proteins of DENV2, DENV3, and DENV4 (Fig. 5e), suggesting that these three $\mathrm{mAbs}$ are great immunological tools which can specifically distinguish the E proteins between ZIKV and DENV. 
a

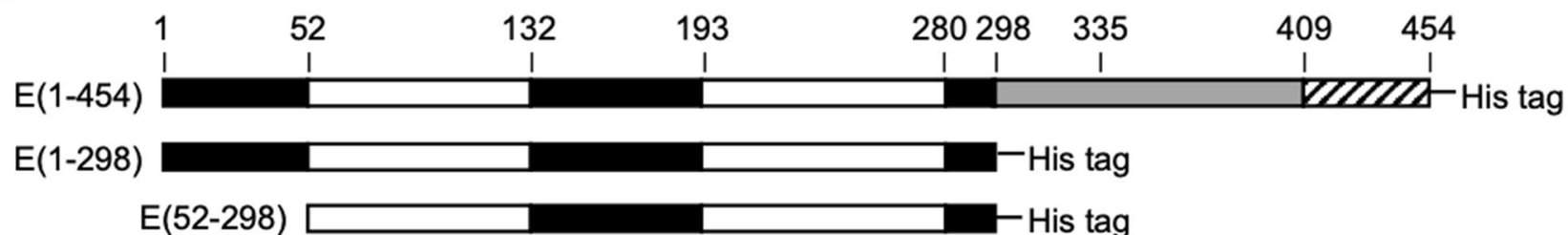

$E(132-298)$

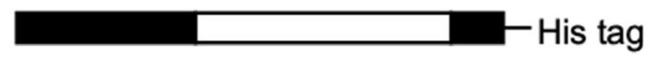

$E(193-298)$

- - His tag

$E(215-298)$

-His tag

E(238-298) $\square$-His tag

Domain I

Domain II

Domain III

Stem domain

His tag

E(277-298) $\square-H i s ~ t a g$

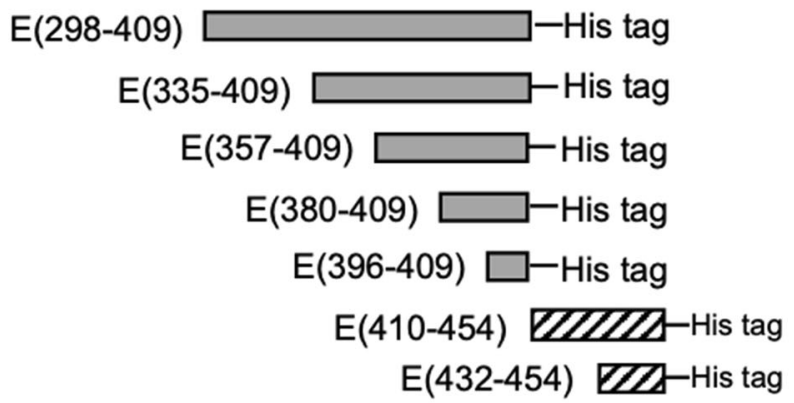

b

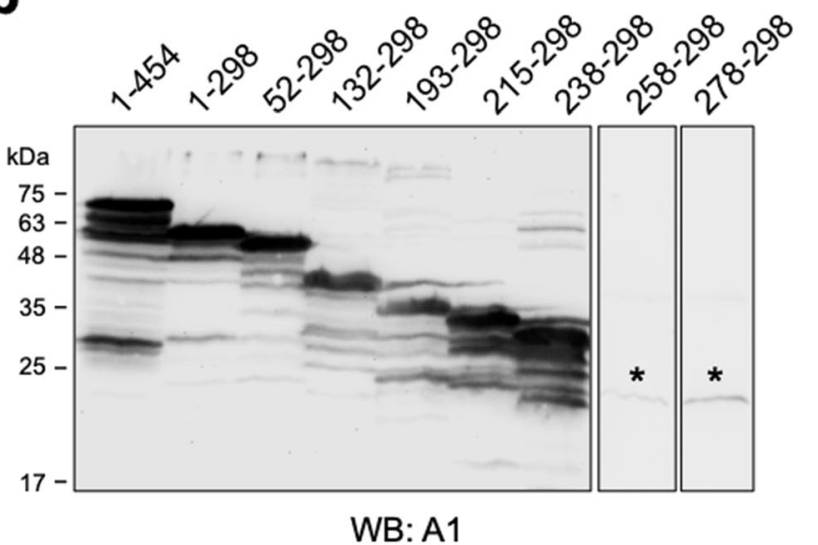

d

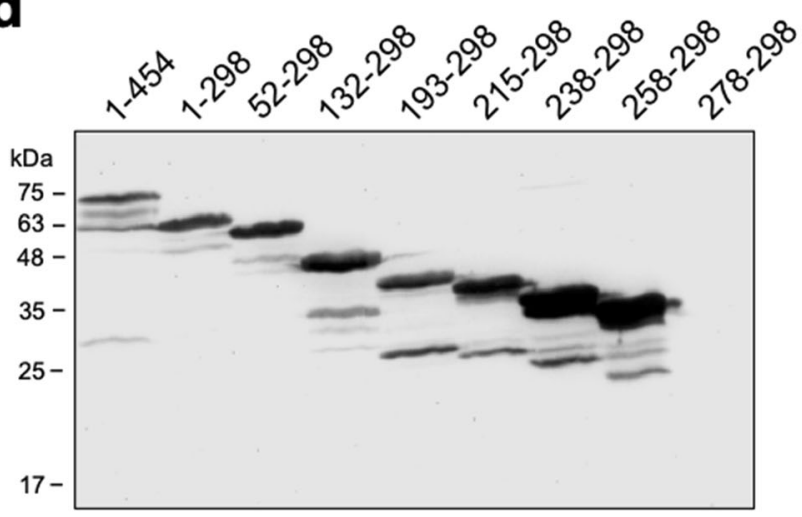

WB: C1
C

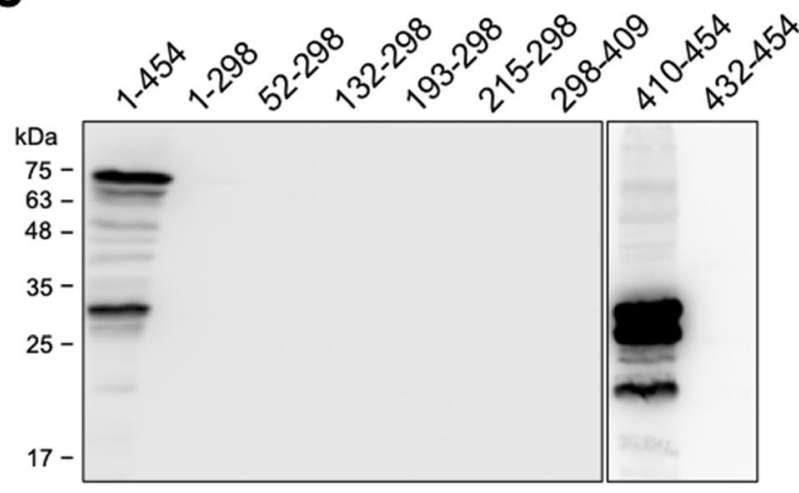

WB: B1

e

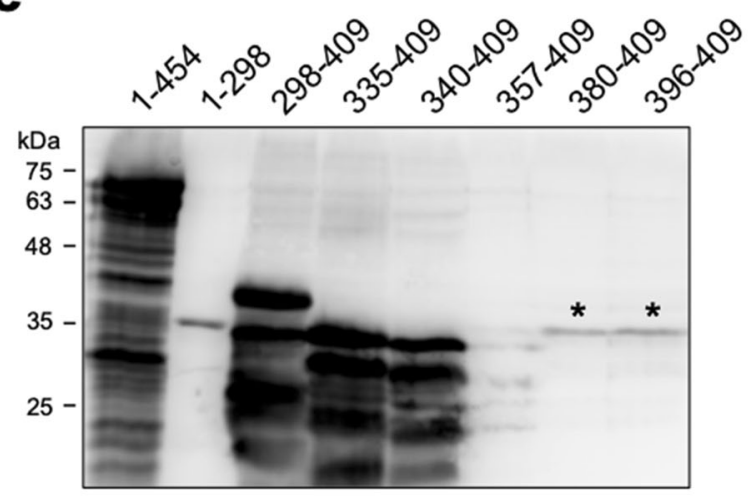

WB: 9E-1 
Fig. 3 Characterization of the binding epitopes of $\mathrm{mAb} A 1, \mathrm{~B} 1, \mathrm{C} 1$, and 9E-1. a The schematic diagram illustrates a series of N-terminally GSTtagged and C-terminally His-tagged truncated ZIKV E protein fragments utilized in the epitope mapping experiments. The N-terminal GST tags are not shown in the diagram. The regions for consisting of domain I, domain II, domain III, or stem domain of ZIKV E protein are presented as black bars, white bars, gray bar, or diagonal striped lines, respectively. The beginning and the ending amino acid residue numbers of the truncated ZIKV E protein fragments are labeled on the left of the indicated fragments. The protein samples were separated on SDS-PAGE and then subjected to WB analysis with mAb A1 (b), B1 (c), C1 (d), or 9E-1 (e). The different WB patterns detected by these four mAbs suggest that they have different binding epitopes. Briefly, the binding epitope of $\mathrm{mAb} \mathrm{A} 1$, $\mathrm{B} 1, \mathrm{C} 1$, or 9E-1 is E(238-257), E(410-431), E(258-277), or E(340-356), respectively. The bands indicated by asterisks on the top are considered non-specific cross-reactions since their molecular weights are not correct

\section{Characterization of ZIKV neutralizing activity with mAbs A1, B1, C1, and 9E-1}

In order to analyze the neutralization activity of mAbs A1, B1, $\mathrm{C} 1$, and 9E-1, the ELISA and PRNT experiments were applied to test whether these four mAbs can bind to the ZIKV virions (strain Thailand/1610acTw) and inhibit ZIKV infection to Vero cells. The result showed that only mAbs B1 and 9E-1 can bind to ZIKV virions (Fig. 6a). To our surprise, mAbs A1 and $\mathrm{C} 1$ cannot bind to ZIKV virions (Fig. 6a). It is possible that the binding epitopes of $\mathrm{mAbs} \mathrm{A} 1$ and $\mathrm{C} 2$ are buried inside the E protein dimers (Fig. 4) and located away from the surface of ZIKV; therefore, they are not accessible for $\mathrm{mAbs} \mathrm{A} 1$ and $\mathrm{C} 1$ binding. The PRNT assays also showed that PBS cannot inhibit ZIKV infection to Vero cells (Fig. 6b), but ZV-54 with known ZIKV neutralization activity (Zhao et al. 2016) can efficiently inhibit ZIKV infection to Vero cells (Fig. 6c). On the contrary, mAbs A1, B1, C1, and 9E-1 and the non-related Anti-H7N9 HA mAb 1C6B cannot inhibit
ZIKV infection to Vero cells (Fig. 6d), indicating that the antibodies targeting to the binding epitopes recognized by these four mAbs do not have ZIKV neutralizing activity.

\section{Detection of ZIKV E protein and virions by LFIA}

Although mAbs B1 and 9E-1 do not have ZIKV neutralizing activity, they can bind to ZIKV virions. In addition, $\mathrm{mAb}$ 9E-1 is highly specific to ZIKV E protein. Thus, $\mathrm{mAbs} B 1$ and 9E-1 were applied for development of the LFIA strip. The experimental results showed that the detection signals become stronger as the increasing amounts of ZIKV E proteins (from 7 to $27 \mu \mathrm{g} / \mathrm{mL}$ ) were loaded on the sample pads (Fig. 7, \#2-4 strips). In another experimental attempt, the LFIA strip can clearly detect ZIKV E protein $(33 \mu \mathrm{g} / \mathrm{mL})$ or ZIKV $\left(6.3 \times 10^{6} \mathrm{pfu} / \mathrm{mL}\right)$ in the culture supernatant (Fig. $7, \# 6-7$ strip).

\section{Discussion}

ZIKV shares a high degree of sequence and structural homology with other flaviviruses, including DENV, WNV, and YFV, resulting in immunological cross-reactivity. However, different flaviviruses circulating in overlapping geographical regions may cause different severe diseases. The accurate diagnostic platforms are needed to distinguish different flavivirus pathogens. In the study, mAbs A1, B1, C1, and 9E-1 with specificity against ZIKV E protein have been generated. We found that the binding epitopes of mAbs A1, B1, and $\mathrm{C} 1$ are highly conserved with the $\mathrm{E}$ proteins of ZIKV and DENV (Fig. 5). Notably, the binding epitope of $\mathrm{mAb} 9 \mathrm{E}-1$ is not conserved with the $\mathrm{E}$ proteins of different flaviviruses, indicating that it is highly specific to

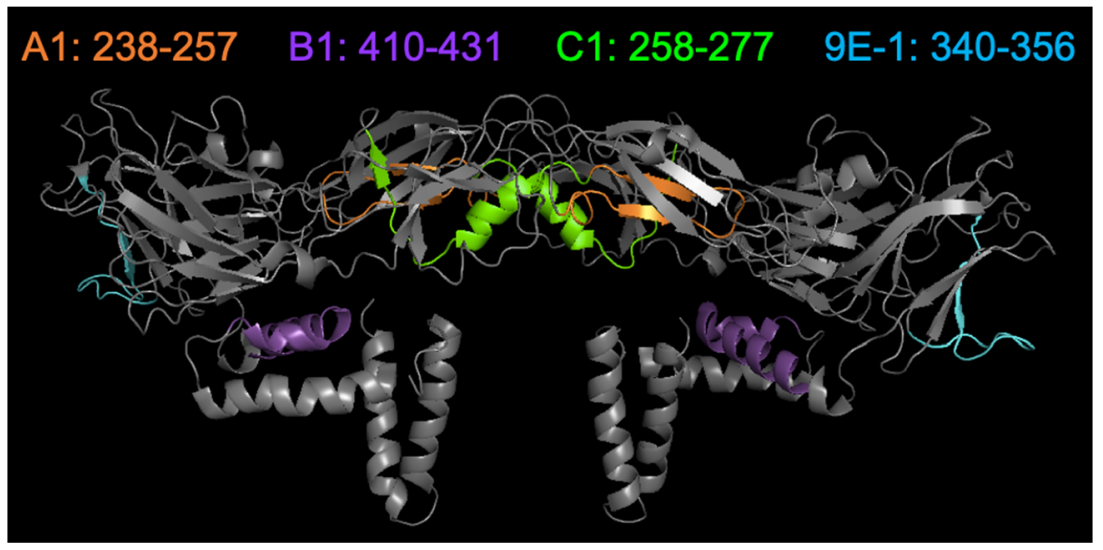

Fig. 4 Mapping of the binding epitopes of mAbs A1, B1, C1, and 9E-1 on the ZIKV E protein dimer. The binding epitope of $\mathrm{mAb} A 1, \mathrm{~B} 1, \mathrm{C} 1$, or 9E-1 is marked in orange, purple, green, or cyan color on the dimeric form of ZIKV E protein (PDB ID: 5IRE), respectively. The binding epitope of mAb A1 (orange color) is buried underneath two beta-sheets.
The binding epitope of $\mathrm{mAb} \mathrm{C1}$ (green color) is located in the interface between two ZIKV E subunits. The binding epitope of mAb B1 (purple color) is located near the stem domain of ZIKV E protein. The binding epitope of mAb 9E-1 (cyan color) is located in the domain III of ZIKV E protein 
a

Binding epitope of mAb A1: E(238-257)

$\begin{array}{ll} & 238 \\ \text { ZIKV-Thailand/1610acTw } & \text { NKEALVEFKDAHAKRQTVVV } \\ \text { ZIKV-Brazil2015 } & \text { NKEALVEFKDAHAKRQTVVV } \\ \text { DENV-1(FJ176780) } & \text { RQDLLVTFKTAHAKKQEVVV } \\ \text { DENV-2(AF204178) } & \text { QKETLVTFKNPHAKKQDVVV } \\ \text { DENV-3(AF317645) } & \text { RKELLVTFKNAHAKKQEVVV } \\ \text { DENV-4(AF289029) } & \text { YKERMVTFKVPHAKRQDVTV } \\ \text { WNV (AY490240) } & \text { NRETLMEFEEPHATKQSVIA } \\ \text { YFV (JX949181) } & \text { EMHHLVEFEPPHAATIRVLA } \\ \text { JEV (L48961) } & \text { NRELLMEFEEAHATKQSVVA }\end{array}$

C

Binding epitope of mAb C1: E(258-277)

ZIKV-Thailand/1610acTw ZIKV-Brazil2015

DENV-1 (FJ176780)

DENV-2 (AF204178)

DENV-3 (AF317645)

DENV-4 (AF289029)

WNV (AY490240)

YFV (JX949181)

JEV ( L48961)

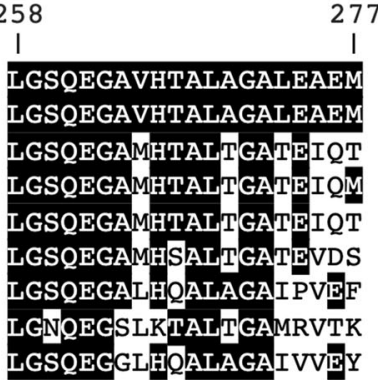

b

Binding epitope of mAb B1: E(410-431)

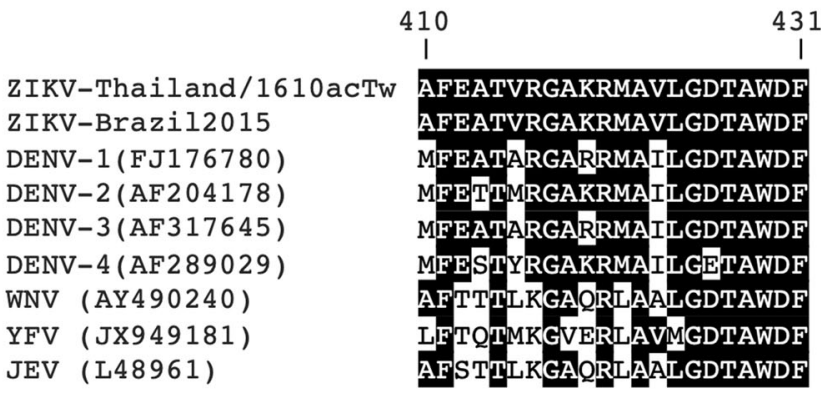

C

Binding epitope of mAb 9E-1: E(340-356)
340

ZIKV-Thailand/1610acTw

ZIKV-Brazil2015

DENV-1 (FJ176780)

DENV-2 (AF204178)

DENV-3 (AF317645)

DENV-4 (AF289029)

WNV (AY490240)

YFV (JX949181)

JEV ( L48961)

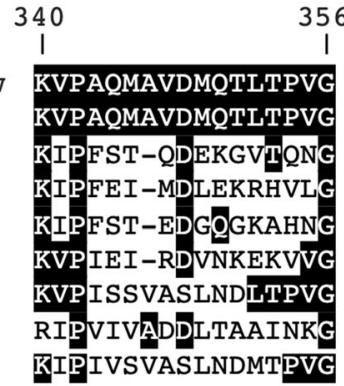

G

KVAQMAVDMQTLTPVG

TPFST-EDGOGKAHNG

VPIEI-RDVNKEKVVG

RIPVIVADDLTAAINKG

KIPIVSVASLNDMTPVG

e

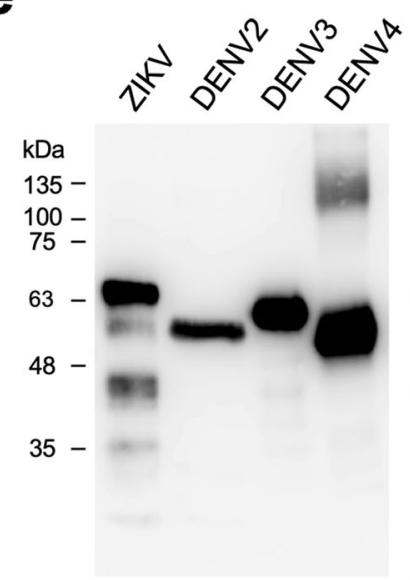

Anti-His
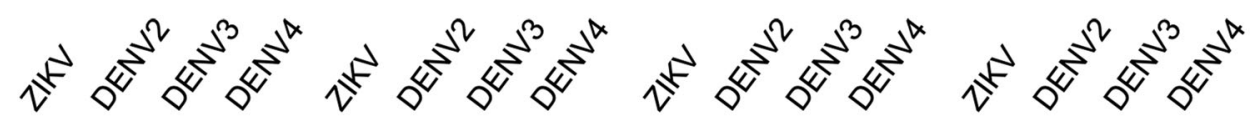

Fig. 5 Alignment of the binding epitopes of mAbs A1 (a), B1 (b), C1 (c), and 9E-1 (d) with other flavivirus E proteins. DENV, dengue virus; WNV, West Nile virus; YFV, yellow fever virus; JEV, Japanese encephalitis virus. The NCBI accession numbers of the E proteins derived for the indicated virus strains are provided in the parentheses. $\mathrm{e}$ The recombinant

\section{B1}

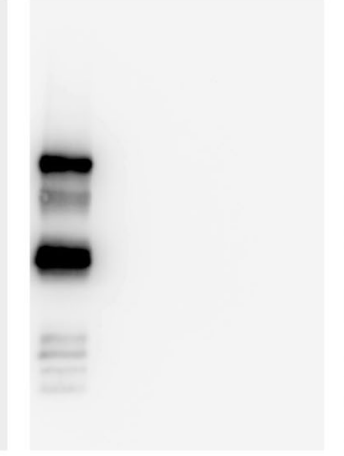

C1

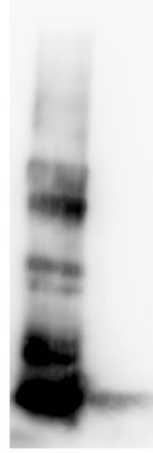

9E-1
E proteins of ZIKV $(2 \mu \mathrm{g})$, DENV2 $(1.75 \mu \mathrm{g})$, DENV3 $(0.42 \mu \mathrm{g})$, and DENV4 $(0.78 \mu \mathrm{g})$ were separated on SDS-PAGE and then transferred to a PVDF membrane for performing the WB analysis with mAbs Anti-His, A1, B1, C1, or 9E-1, respectively. The numbers labeled on the left of the designated ticks are the molecular weight standards in $\mathrm{kDa}$ unit

mAbs A1 and $\mathrm{C} 1$ binding. The PRNT experimental results reveal that $\mathrm{mAbs} \mathrm{A} 1, \mathrm{~B} 1, \mathrm{C} 1$, and 9E-1 do not have ZIKV neutralizing activity, suggesting that using the binding epitopes recognized by these four mAbs as the antigens or subunit vaccines may not be able to induce potent neutralizing antibodies. These data are informative evidence for ZIKV vaccine development. 


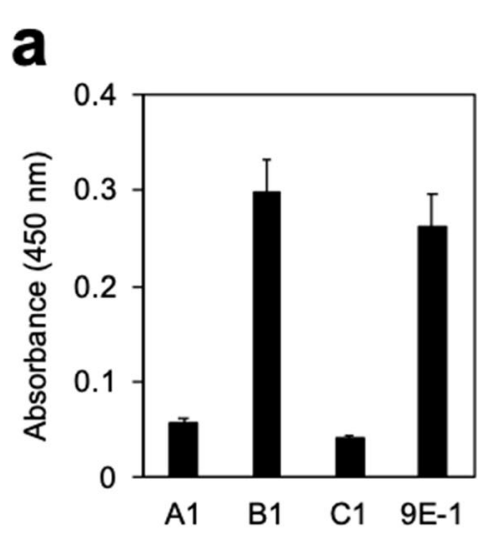

0
$\mathrm{Ab}(\mu \mathrm{g} / \mathrm{mL})$

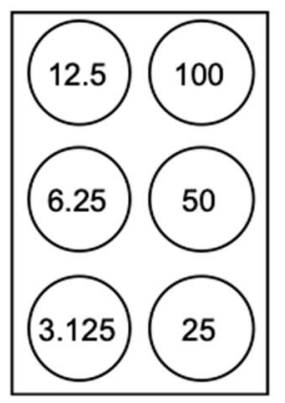

Fig. 6 Analysis of the binding affinity and neutralization activity of mAbs A1, B1, C1, and 9E-1 against ZIKV. a The virus virions of ZIKV isolate Thailand/1610acTw were coated on a 96 -well plate and then subjected to ELISA analysis with mAbs, A1, B1, C1, or 9E-1, respectively. The results were examined quantitatively by measuring the absorbance at $450 \mathrm{~nm}$. Values are means \pm S.D. from three independent experiments. For conducting the PRNT experiments, PBS (b), a batch of two-fold serially diluted ZV-54 antibody solutions (starting from $10 \mu \mathrm{g}$ /

Some ZIKV neutralizing antibodies derived from the ZIKV infected patients target to the domain III of ZIKV E protein (Stettler et al. 2016; Wang et al. 2019). Additionally, immunization of the domain III of ZIKV E protein induces specific and neutralizing immune responses against ZIKV (Yang et al. 2017). Nonetheless, it was reported that there are three spatially distinct epitopes in the domain III of ZIKV E protein, including the lateral ridge, C-C' loop, and $\mathrm{ABDE}$ sheet regions (Zhao et al. 2016). The $\mathrm{mAbs} Z \mathrm{Z}-54$ and ZV-67 targeting to the lateral ridge (A311, A333, T335, E370, N371, E393, K394) performed potent ZIKV neutralizing activity, whereas mAbs ZV-48 and ZV-64 targeting to the C-C' loop (K340, Q350, T351, T353, P354) showed reduced inhibitory activity against ZIKV (Zhao et al. 2016). Our PRNT experimental results also demonstrated that $\mathrm{mAb} Z \mathrm{ZV}-54$ can markedly inhibit ZIKV (strain Thailand/1610acTw) infection to Vero cells (Fig. 6c). The binding epitope E(340-356) of $\mathrm{mAb} 9 \mathrm{E}-1$ is also mainly located in the C-C' loop of domain III of ZIKV E protein. We also found that $\mathrm{mAb} 9 \mathrm{E}-1$ does not have ZIKV neutralizing activity (Fig. 6d). Data from ours and other groups suggest that the domain III of ZIKV E protein
C
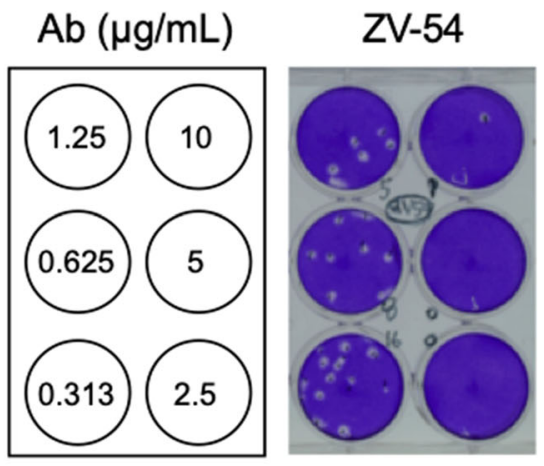

C1

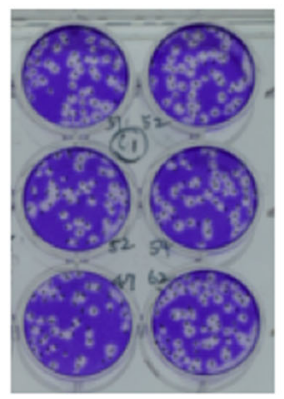

$9 \mathrm{E}-1$

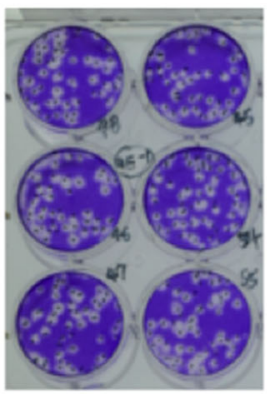

1C6B

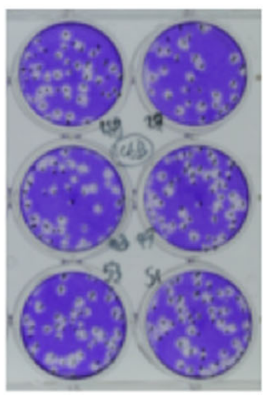

$\mathrm{mL}$ as indicated in the schematic diagram on the left) (c), and a batch of A1, B1, C1, 9E-1, or 1C6B (an Anti-H7N9 HA mAb) antibody solutions (starting from $100 \mu \mathrm{g} / \mathrm{mL}$ as indicated in the schematic diagram on the left) (d) were pre-incubated with 100 PFU of ZIKV for performing the PRNT assays as described in the "Materials and methods" section. The results showed that mAbs A1, B1, C1, and 9E-1 do not have ZIKV neutralizing activity

can be targeted by multiple types of specific antibodies with distinct neutralizing activity.

ZIKV is circulated in areas that are also highly endemic for DENV. Many studies have reported that broad-spectrum antibodies that neutralize Zika virus can be isolated from patients infected with DENV or vice versa (Barba-Spaeth et al. 2016; Dussupt et al. 2020; Gunawardana and Shaw 2018; Priyamvada et al. 2016; Stettler et al. 2016; Swanstrom et al. 2016; Zhang et al. 2016), indicating that the immunological cross-reactivity may exist among anti-ZIKV and anti-DENV antibodies. However, the broad-spectrum antibodies are not suitable for developing as the diagnostic platforms to distinguish different flaviviruses precisely. A double-antibody sandwich ELISA to detect the ZIKV NS1 protein (nonstructural protein 1) in individuals newly infected with the ZIKV has been developed (Zhang et al. 2018). Another NS1-based rapid test that utilized mAb pairs to detect and distinguish ZIKV and another four serotypes of DENV was also reported (Bosch et al. 2017). However, the immunological cross-reactivity still exists in these two platforms. In this work, we found that mAbs A1, C1, and 9E-1 do not have 


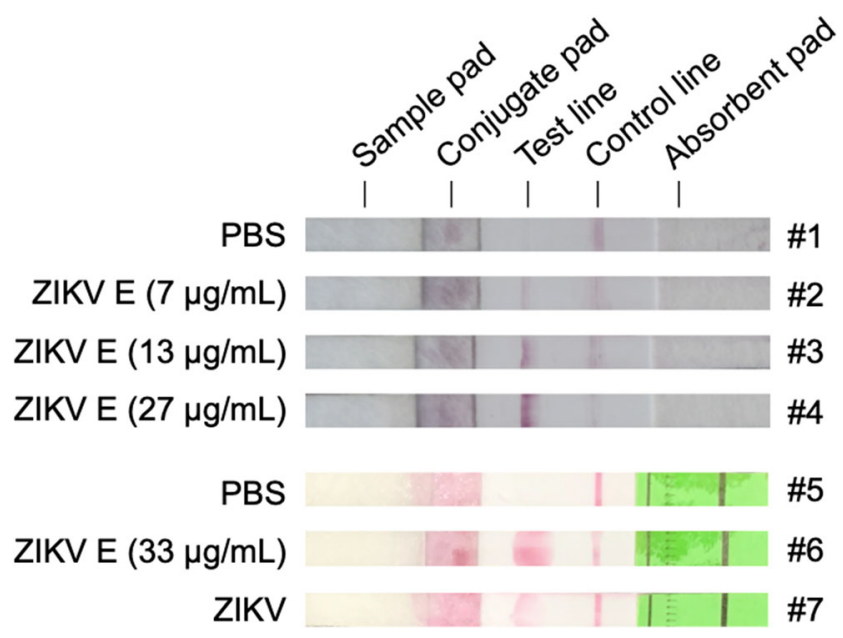

Fig. 7 Detection of ZIKV E proteins and virions by LFIA. The LFIA strip (\#1-\#7) was composed of four main materials including sample pad, conjugate pad, nitrocellulose membrane, and absorbent pad. mAb B1 was conjugated with colloidal gold particles and loaded on the conjugate pad. $\mathrm{mAb} 9 \mathrm{E}-1$ was loaded on the test line. Goat anti-mouse IgG antibody was loaded on the control line. The assay was conducted by adding PBS, the purified ZIKV E proteins $(7-33 \mu \mathrm{g} / \mathrm{mL})$, or ZIKV $\left(6.3 \times 10^{6} \mathrm{pfu} / \mathrm{mL}\right)$ on the sample pad to start the LFIA. The results were interpreted within 10 min. The colloidal gold particles can only be observed on the test line while using the purified ZIKV E proteins or ZIKV as the test sample

cross-reactivity against the E proteins of DENV2, DENV3, and DENV4 (Fig. 5e), implying that these three mAbs are excellent immunological tools for distinguishing ZIKV from DENV.

It is noted that the primary antigen for recognition by $\operatorname{IgG}$ and IgM during flavivirus infections is the viral $\mathrm{E}$ protein. Therefore, E protein is considered the major target antigen for diagnostics of flavivirus infections. However, the similarity of the flavivirus E proteins may also cause additional problems of immunological cross-reactivity, leading to falsepositive results. It is known that the lateral flow immunoassays are excellent rapid diagnostic tests (point-of-care devices) in terms of their ease of use, sensitivity, specificity, and scalability for manufacturing. A rapid diagnostic test kit for detecting $\mathrm{IgG} / \mathrm{IgM}$ antibodies against $\mathrm{ZIKV}$ using $\mathrm{mAbs}$ against the E protein and NS1 protein of ZIKV has been developed for improving the sensitivity and specificity (Kim et al. 2018). Here we show that the binding epitope of mAb 9E-1 is not conserved with the $\mathrm{E}$ proteins of different flaviviruses; therefore, it is an excellent tool for developing as the specific LFIA (Fig. 7) or other immunological platforms for diagnostics of ZIKV.

Acknowledgements The authors are thankful to the excellent technical assistance from Technology Commons, College of Life Science, National Taiwan University.

Author contribution CJL, PHH, HWC, and SCC conceived and designed the research. HWC and SCC acquired funds and conducted experiments. CJL and PHH performed experiments. CJL, PHH, HWC, and SCC analyzed data and wrote the manuscript.

Funding This work was supported by grants from the Ministry of Science and Technology, Taiwan (MOST108-2313-B-002-011 and MOST107-2313-B-002-045), National Health Research Institute, Taiwan (NHRI-EX109-10721SC), and National Taiwan University (108L883703 and 109L883703).

Data availability All data associated with this study are included in the paper. All plasmids generated in the study are available from the corresponding author on reasonable request.

\section{Declarations}

Ethical statement The animal experiment was approved by the Institutional Animal Care and Use Committee (IACUC) of National Taiwan University (IACUC Approval Number: NTU107-EL-00023) and implemented in accordance with the animal care and ethics guidelines. The article does not contain any studies with human participants performed by any of the authors.

Conflict of interest The authors declare no competing interests.

\section{References}

Barba-Spaeth G, Dejnirattisai W, Rouvinski A, Vaney MC, Medits I, Sharma A, Simon-Loriere E, Sakuntabhai A, Cao-Lormeau VM, Haouz A, England P, Stiasny K, Mongkolsapaya J, Heinz FX, Screaton GR, Rey FA (2016) Structural basis of potent Zikadengue virus antibody cross-neutralization. Nature 536(7614):4853

Bosch I, de Puig H, Hiley M, Carre-Camps M, Perdomo-Celis F, Narvaez CF, Salgado DM, Senthoor D, O'Grady M, Phillips E, Durbin A, Fandos D, Miyazaki H, Yen CW, Gelvez-Ramirez M, Warke RV, Ribeiro LS, Teixeira MM, Almeida RP, Munoz-Medina JE, Ludert JE, Nogueira ML, Colombo TE, Terzian ACB, Bozza PT, Calheiros AS, Vieira YR, Barbosa-Lima G, Vizzoni A, Cerbino-Neto J, Bozza FA, Souza TML, Trugilho MRO, de Filippis AMB, de Sequeira PC, Marques ETA, Magalhaes T, Diaz FJ, Restrepo BN, Marin K, Mattar S, Olson D, Asturias EJ, Lucera M, Singla M, Medigeshi GR, de Bosch N, Tam J, Gomez-Marquez J, Clavet C, Villar L, Hamad-Schifferli K, Gehrke L (2017) Rapid antigen tests for dengue virus serotypes and Zika virus in patient serum. Sci Transl Med 9(409):eaan1589

Bradford MM (1976) A rapid and sensitive method for the quantitation of microgram quantities of protein utilizing the principle of protein-dye binding. Anal Biochem 72:248-254

Cheng YC, Chang SC (2021) Development and biochemical characterization of the monoclonal antibodies for specific detection of the emerging $\mathrm{H} 5 \mathrm{~N} 8$ and $\mathrm{H} 5 \mathrm{Nx}$ avian influenza virus hemagglutinins. Appl Microbiol Biotechnol 105(1):235-245

Chiang YW, Li CJ, Su HY, Hsieh KT, Weng CW, Chen HW, Chang SC (2021) Development of mouse monoclonal antibody for detecting hemagglutinin of avian influenza $\mathrm{A}(\mathrm{H} 7 \mathrm{~N} 9)$ virus and preventing virus infection. Appl Microbiol Biotechnol 105(8):3235-3248

Dupont-Rouzeyrol M, Biron A, O'Connor O, Huguon E, Descloux E (2016) Infectious Zika viral particles in breastmilk. Lancet 387(10023): 1051

Dussupt V, Sankhala RS, Gromowski GD, Donofrio G, De La Barrera RA, Larocca RA, Zaky W, Mendez-Rivera L, Choe M, Davidson E, McCracken MK, Brien JD, Abbink P, Bai H, Bryan AL, Bias CH, 
Berry IM, Botero N, Cook T, Doria-Rose NA, Escuer AGI, Frimpong JA, Geretz A, Hernandez M, Hollidge BS, Jian N, Kabra K, Leggat DJ, Liu J, Pinto AK, Rutvisuttinunt W, Setliff I, Tran U, Townsley S, Doranz BJ, Rolland M, McDermott AB, Georgiev IS, Thomas R, Robb ML, Eckels KH, Barranco E, Koren M, Smith DR, Jarman RG, George SL, Stephenson KE, Barouch DH, Modjarrad K, Michael NL, Joyce MG, Krebs SJ (2020) Potent Zika and dengue cross-neutralizing antibodies induced by Zika vaccination in a dengue-experienced donor. Nat Med 26(2):228-235

Gourinat AC, O'Connor O, Calvez E, Goarant C, Dupont-Rouzeyrol M (2015) Detection of Zika virus in urine. Emerg Infect Dis 21(1):84 86

Gunawardana SA, Shaw RH (2018) Cross-reactive dengue virus-derived monoclonal antibodies to Zika virus envelope protein: panacea or pandora's box? BMC Infect Dis 18(1):641

Kim YH, Lee J, Kim YE, Chong CK, Pinchemel Y, Reisdorfer F, Coelho JB, Dias RF, Bae PK, Gusmao ZPM, Ahn HJ, Nam HW (2018) Development of a rapid diagnostic test kit to detect IgG/IgM antibody against Zika virus using monoclonal antibodies to the envelope and non-structural protein 1 of the virus. Korean J Parasitol 56(1): $61-70$

Kindhauser MK, Allen T, Frank V, Santhana RS, Dye C (2016) Zika: the origin and spread of a mosquito-borne virus. Bull World Health Organ 94(9):675-686C

Marchette NJ, Garcia R, Rudnick A (1969) Isolation of Zika virus from Aedes aegypti mosquitoes in Malaysia. Am J Trop Med Hyg 18(3): 411-415

Musso D, Roche C, Nhan TX, Robin E, Teissier A, Cao-Lormeau VM (2015) Detection of Zika virus in saliva. J Clin Virol 68:53-55

Perera-Lecoin M, Meertens L, Carnec X, Amara A (2013) Flavivirus entry receptors: an update. Viruses 6(1):69-88

Priyamvada L, Quicke KM, Hudson WH, Onlamoon N, Sewatanon J, Edupuganti S, Pattanapanyasat K, Chokephaibulkit K, Mulligan MJ, Wilson PC, Ahmed R, Suthar MS, Wrammert J (2016) Human antibody responses after dengue virus infection are highly cross-reactive to Zika virus. Proc Natl Acad Sci U S A 113(28): 7852-7857

Roby JA, Setoh YX, Hall RA, Khromykh AA (2015) Post-translational regulation and modifications of flavivirus structural proteins. J Gen Virol 96(Pt 7):1551-1569
Shin YC, Tang SJ, Chen JH, Liao PH, Chang SC (2011) The molecular determinants of NEDD8 specific recognition by human SENP8. PLoS One 6(11):e27742

Slon Campos JL, Mongkolsapaya J, Screaton GR (2018) The immune response against flaviviruses. Nat Immunol 19(11):1189-1198

Stettler K, Beltramello M, Espinosa DA, Graham V, Cassotta A, Bianchi S, Vanzetta F, Minola A, Jaconi S, Mele F, Foglierini M, Pedotti M, Simonelli L, Dowall S, Atkinson B, Percivalle E, Simmons CP, Varani L, Blum J, Baldanti F, Cameroni E, Hewson R, Harris E, Lanzavecchia A, Sallusto F, Corti D (2016) Specificity, cross-reactivity, and function of antibodies elicited by Zika virus infection. Science 353(6301):823-826

Swanstrom JA, Plante JA, Plante KS, Young EF, McGowan E, Gallichotte EN, Widman DG, Heise MT, de Silva AM, Baric RS (2016) Dengue virus envelope dimer epitope monoclonal antibodies isolated from dengue patients are protective against Zika virus. mBio 7(4):e01123-16

Wang L, Wang R, Wang L, Ben H, Yu L, Gao F, Shi X, Yin C, Zhang F, Xiang Y, Zhang L (2019) Structural basis for neutralization and protection by a Zika virus-specific human antibody. Cell Rep 26(12):3360-3368

Yang M, Dent M, Lai H, Sun H, Chen Q (2017) Immunization of Zika virus envelope protein domain III induces specific and neutralizing immune responses against Zika virus. Vaccine 35(33):4287-4294

Zhang S, Kostyuchenko VA, Ng TS, Lim XN, Ooi JSG, Lambert S, Tan TY, Widman DG, Shi J, Baric RS, Lok SM (2016) Neutralization mechanism of a highly potent antibody against Zika virus. Nat Commun 7:13679

Zhang L, Du X, Chen C, Chen Z, Zhang L, Han Q, Xia X, Song Y, Zhang J (2018) Development and characterization of double-antibody sandwich ELISA for detection of Zika virus infection. Viruses 10(11):634

Zhao H, Fernandez E, Dowd KA, Speer SD, Platt DJ, Gorman MJ, Govero J, Nelson CA, Pierson TC, Diamond MS, Fremont DH (2016) Structural basis of Zika virus-specific antibody protection. Cell 166(4):1016-1027

Publisher's note Springer Nature remains neutral with regard to jurisdictional claims in published maps and institutional affiliations. 